\title{
A flipped forward view for healthcare
}

\author{
Cath Brizzell deputy editor, The BMJ
}

The recent publication of the NHS's Five Year Forward View by NHS England's chief executive, Simon Stevens, has been described as "radical" by some reports. One proposal is that general practices would offer many of the services currently confined to hospitals. It is generally agreed that it will be a "huge challenge" to deliver what has been outlined in the five year time scale (doi:10.1136/bmj.g6484).

Apart from Stevens's call to political parties for a major increase in funding to fill an £8bn gap, he also proposes a focus on "unleashing innovation and improvement" by finding new ways to tap into three sources of what he calls "renewable energy." These are the role of patients in their own healthcare, the part that carers and volunteers play in the community, and finally the "passion and drive of the workers."

Stevens, who has experience of international healthcare systems, may need to protect his vision for the NHS from the constraints of existing practices and traditional professional boundaries. He says, "We'd be daft to ignore excellent ideas just because they are not invented here."

In their analysis article Maureen Bisognano and Dan Schummers of the Institute for Healthcare Improvement in Massachusetts agree with a radical approach, urging us to "flip healthcare" to develop innovative models of care that they say can improve the delivery of care and reduce costs (doi:10.1136/bmj.g5852). The model is adapted from education: it shifts teachers in the classroom from being the "sage on the stage" to the "guide on the side," helping to identify students who are most in need but least inclined to seek help. The authors discuss how truly patient centred healthcare "must consider and seek to understand the entire spectrum of social and economic factors that affect a person's health." Asking patients "What matters to you?" as well as "What's the matter?" would help to inform everything we do, they say.

With that in mind, Abul Siddiky and colleagues in their clinical review of the management of patients with arteriovenous fistulas highlight the global increase in numbers of patients needing renal replacement therapy, many of whom are experienced in self management within their community settings (doi:10.1136/ bmj.g6262). The authors provide tips for non-specialist clinicians on what to do when things go wrong, including dealing with infection, steal syndrome, and cardiac failure.

And amid all the talk of reorganisation, a personal view by Richard Wakeford (doi:10.1136/bmj.g6245) in response to Labour's announcement to recruit 8000 more GPs (doi:10.1136/ bmj.g5864) says that although more GPs are needed right now, there is an urgent need to tackle the low number of medical students aiming to enter general practice.

And so with elections just some months away Stevens calls for action over and above current initiatives, saying, "It's time to roll up our sleeves, pull together and get on with it." If the NHS is to survive, a forward thinking plan is the only way. Ambitious and ideological, yes, but if a truly patient centred approach is embraced by even more clinicians, who knows what might be possible?

Cite this as: BMJ 2014;349:96515

๑ BMJ Publishing Group Ltd 2014 